\title{
Chapter 6 \\ Vertical Migration of Radiocesium Fallout in Soil in Fukushima
}

\author{
Sho Shiozawa
}

\begin{abstract}
The vertical migration of radiocesium fallout in the soil was monitored for 1 year at several locations in Fukushima after the nuclear power plant explosion. We determined the vertical gamma ray intensity profiles in boreholes in the soil using a scintillation survey meter with a lead collimator to restrict the incoming radiation, only allowing horizontal detection. The average migration distances of radiocesium at two time points were accurately determined based on the difference in the depth of the centroids of two gamma ray intensity profiles. The results showed that although the convective velocity of radiocesium was unexpectedly as high as $1 / 10$ th of the velocity of the infiltrating rainfall water 2-3 months after the nuclear plant accident, the velocity decreased to $1 / 100$ th-1/200th of that of the water after 6-12 months. This indicated that strong fixation of radiocesium to clay particles occurred during the initial 2-3 months. Radiocesium uptake by plant roots may have decreased remarkably along with the mobility of radiocesium in the soil.
\end{abstract}

Keywords Collimator $\bullet$ Distribution coefficient $\bullet$ Gamma ray $\bullet$ Migration velocity of $\mathrm{Cs} \bullet$ Sorption $\bullet$ Water flux in soil

\section{Abbreviation}

Cs Cesium

\footnotetext{
S. Shiozawa $(\bowtie)$

Graduate School of Agricultural and Life Sciences, The University of Tokyo,

1-1-1 Yayoi, Bunkyo-ku, Tokyo 113-8657, Japan

e-mail: asho@mail.ecc.u-tokyo.ac.jp
} 


\subsection{Retardation of Cesium Migration as a Result of Fixation to Soil Solids}

Cesium (Cs) is soluble in water as a univalent cation. In general, the cation is fixed on any solid surface with a negative electric charge, such as soil particles or organic matter in soil. The fixed cation is exchanged by any other cation; in a manner that the concentrations of the fixed cations are in equilibrium with the concentrations of other cations in the soil water. Plant roots can easily absorb this form of Cs. This adhesion of Cs on soil solids is referred to as "weak fixation" in the present study. On the other hand, Cs strongly fixes to other types of clay crystals such as silicate sheets. The strongly fixed Cs ions on these clay particles are rarely replaced by other cations as soluble ions, and thus are seldom absorbed by plant roots.

The average water flux (q) in the surface soil over time is calculated as the amount of precipitation minus the soil evaporation, i.e., approximately $q=1,000 \mathrm{~mm} /$ year in Japan as well as in Fukushima. The corresponding average velocity of water molecules (v) is calculated as the water flux divided by the volumetric water content $(\theta)$, the value of which is, in case of a typical $\theta$ value of 0.5 is approximately $\mathrm{v}=\mathrm{q} / \theta=2 \mathrm{~m} /$ year. However, the average velocity of Cs is retarded because of its fixation to soil solids. The ratio of the average velocity of Cs relative to that of water molecules is calculated based on the ratio of Cs present in the soil water to Cs in the total soil, including fixed Cs (Fig. 6.1), which is given by the following equation:

$$
\frac{1}{\mathrm{Re}} \equiv \frac{\text { velocity of } \mathrm{Cs}}{\text { velocity of } \mathrm{H}_{2} \mathrm{O}}=\frac{\mathrm{Cs} \text { in soil water }}{\mathrm{Cs} \text { in overall soil }}
$$

Assuming a sorption equilibrium of Cs concentrations on solids and water, and reversible exchange between the two phases, the distribution coefficient $\mathrm{K}_{\mathrm{d}}$ can be introduced, which is defined as follows:

$$
\mathrm{K}_{\mathrm{d}} \equiv \frac{\text { Cs concentration in solid phase }[\mathrm{Bq} / \mathrm{kg}]}{\text { Cs concentration in liquid phase }[\mathrm{Bq} / \mathrm{L}]}
$$

Re can be calculated using $\mathrm{K}_{\mathrm{d}}$ as follows:

$$
\operatorname{Re}=1+\frac{K_{d} \rho_{b}}{\theta} \approx \frac{K_{d} \rho_{b}}{\theta}
$$

where $\rho_{\mathrm{b}}$ is the dry bulk density. In general, $K_{\mathrm{d}}$ indicates the mobility (immobility) of a specific ion in a specific soil. Re defined in Eq. (6.1) is an inverse indicator of the mobility of $\mathrm{Cs}$ in the soil and also an indicator of the difficulty in Cs uptake by plant roots because plant roots absorb $\mathrm{Cs}$ in the form of ions from the soil water adjacent to the roots.

The IAEA handbook (IAEA 2010) provides mean values of $\mathrm{K}_{\mathrm{d}}$ for $\mathrm{Cs}$ as $\mathrm{K}_{\mathrm{d}}=1,200 \mathrm{~L} / \mathrm{kg}$ for 469 soils, $\mathrm{K}_{\mathrm{d}}=530 \mathrm{~L} / \mathrm{kg}$ for sand, and $\mathrm{K}_{\mathrm{d}}=270 \mathrm{~L} / \mathrm{kg}$ for organic soil. The $K_{d}$ values for $\mathrm{Cs}$ are one to two order greater than radiostrontium ( $\mathrm{Sr}$ ), which is another typical radionuclide released by nuclear explosions ( $\mathrm{Sr}$ was not released during the Fukushima accident), i.e., its mean value is $\mathrm{K}_{\mathrm{d}}=52 \mathrm{~L} / \mathrm{kg}$; 
Fig. 6.1 Effects of cesium (Cs) fixation to soil solids. Cesium molecules dissolved in the soil water could only migrate with the water and were absorbed by the plant root

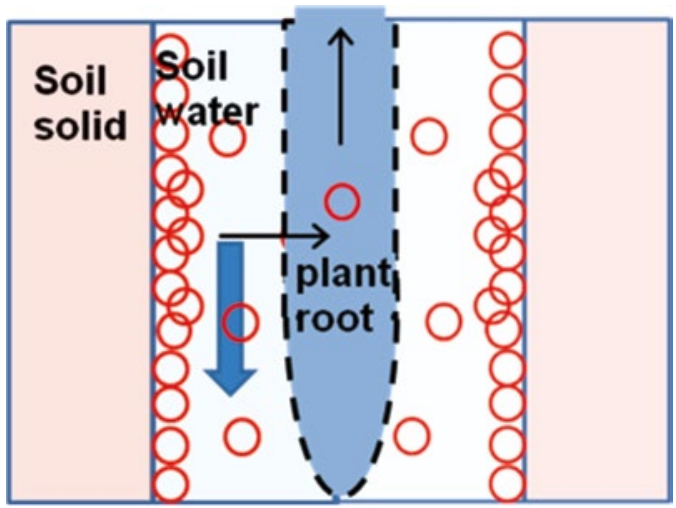

therefore, $\mathrm{Cs}$ is much less mobile in soil. The values of $\mathrm{K}_{\mathrm{d}}$ measured in 30 Japanese paddy soils ranged from $\mathrm{K}_{\mathrm{d}}=270 \mathrm{~L} / \mathrm{kg}$ to $\mathrm{K}_{\mathrm{d}}=17,000 \mathrm{~L} / \mathrm{kg}$ with a geometric average of $2,300 \mathrm{~L} / \mathrm{kg}$ (Kamei-Ishikawa et al. 2008). However, their $\mathrm{K}_{\mathrm{d}}$ values were obtained in laboratory equilibrium conditions after shaking the suspended solutions in test tubes for several days; thus, the actual value of Re in the field could be very different from that calculated in the laboratory based on the $\mathrm{K}_{\mathrm{d}}$ value. Given typical values of $\theta=0.5$ and $\rho_{b}=1.0 \mathrm{~g} / \mathrm{cm}^{3}$, the value for Re calculated from $K_{d}$ is approximately twice of that of $\mathrm{K}_{\mathrm{d}}$.

Field investigations in Sweden after the Chernobyl accident (Rosen et al. 1999) showed that the initial velocity of Cs during the first year (1987) was 5-10 mm/year, which decreased to $1-4 \mathrm{~mm} /$ year in the next 5-8 years, indicating that the strong fixation of Cs to soil particles proceeded gradually for years. Thus, the values of Re may be approximately 100-1,000. This investigation also showed that the Cs velocity in organic soil was several times that in mineral soil.

\subsection{Cs Concentration Profile in Soil 2 Months After the Fallout}

Figure 6.2 shows vertical concentration profiles of radiocesium $\left({ }^{134} \mathrm{C}\right.$ and $\left.{ }^{137} \mathrm{Cs}\right)$ determined in an undisturbed paddy field in Fukushima Prefecture before plowing on May 24th, 2011, approximately 2 months after the radiocesium fallout (Shiozawa et al. 2011). The top $0-15 \mathrm{~cm}$ of the soil was sampled, which was separated into six layers of $1-5 \mathrm{~cm}$ thickness. The resulting concentration profile indicated that $88 \%$ of ${ }^{134} \mathrm{Cs}+{ }^{137} \mathrm{Cs}$ was present within the $0-3 \mathrm{~cm}$ layer and $96 \%$ within the $0-5 \mathrm{~cm}$ layer. However, although most of the radiocesium remained within the top few centimeters of the surface layer, some of it had already reached the 10-15 cm layer. The mean traveling distances of ${ }^{134} \mathrm{Cs}$ and ${ }^{137} \mathrm{Cs}$ were calculated from the profile as $1.74 \mathrm{~cm}$. On the other hand, the mean traveling distance of water molecules during the 70-day period was estimated based on the (precipitation-evaporation)/ (volumetric water content) as approximately $20 \mathrm{~cm}$. Therefore, the convective 

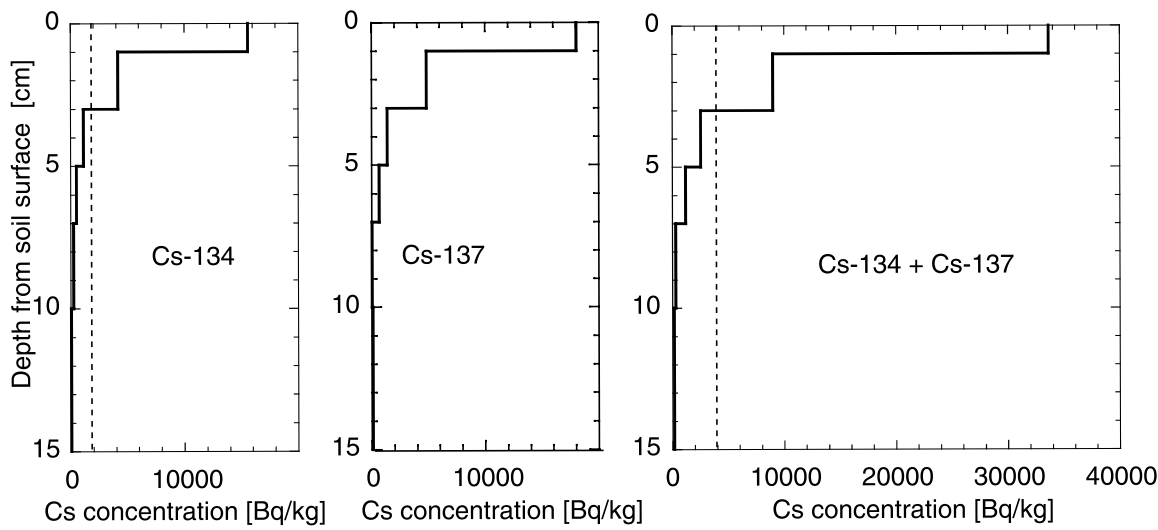

Fig. 6.2 Radiocesium concentration profiles in the soil on May 24th, 2011, for an undisturbed paddy field (solid line) and a plowed paddy field (dashed line) (Shiozawa et al. 2011)

velocity of Cs was 1/10th of that of water due to the sorption of Cs on soil particles. However, this Cs velocity was two to three orders greater than that calculated based on laboratory determined distribution coefficients $\left(K_{\mathrm{d}}\right)$ for Japanese paddy soils (Kamei-Ishikawa et al. 2008), indicating that the movement of Cs in the field was very different from the sorption equilibrium.

It is difficult to determine Cs migration distances of several millimeters by comparing the two vertical concentration profiles obtained by soil sampling at different time points because the Cs concentration profiles are not in exactly the same soil positions. They vary considerably even if they are obtained at the same time. Thus, we developed a method for measuring Cs migration distances of several millimeters in the soil over a period of several months by comparing two vertical gamma-ray intensity profiles, which were measured using a scintillation survey meter inside monitoring boreholes.

\subsection{Method Used to Monitor the Cs Migration Distance in a Borehole}

\subsubsection{Collimator and Monitoring Pipe}

To measure the intensity of horizontal incoming $\gamma$-rays at each depth in the soil, the gamma-ray detector was enclosed by a barrier (lead) that had a slit window around the detector to restrict any incoming radiation except for that in the horizontal direction. A cylindrical scintillation probe (Health Physics Instruments, Model 5000) measuring $35 \mathrm{~mm}$ in diameter was covered with a handmade lead collimator that 

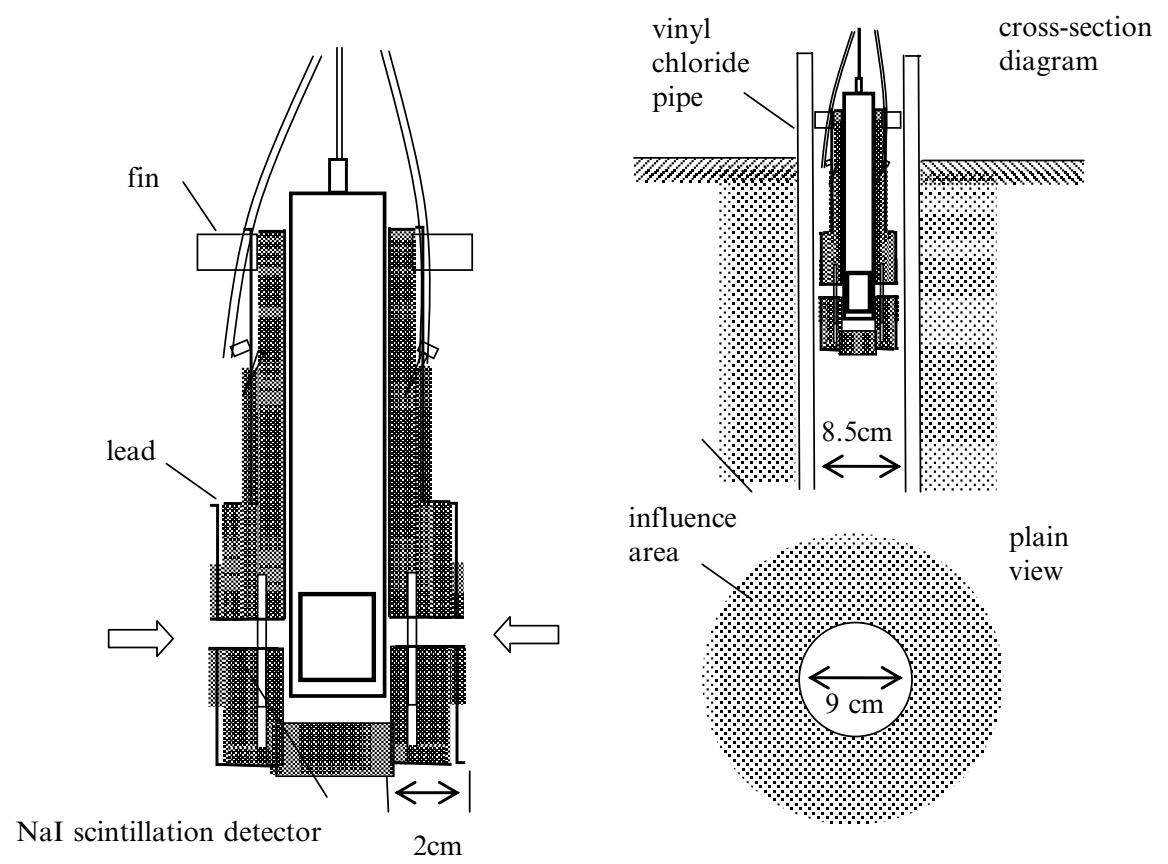

Fig. 6.3 Lead collimator for the scintillation probe and the soil gamma-ray distribution monitoring pipe in a borehole

had a slit window around the scintillation detector (Fig. 6.3). The collimator consisted of an upper part (main body) and a lower part, which were separated by the window. The lower part could slide in an acryl guide cylinder and the base was fixed onto the main body such that the vertical width of the slit window was variable in a range of $0-2 \mathrm{~cm}$. The lower part of the collimator was connected to the upper part by a rubber band, whereas pieces of polystyrene spacers were placed in the window to determine the size of the window. The horizontal depth of the slit window was $2 \mathrm{~cm}$. The collimator was made from $2-\mathrm{mm}$ thick lead plate. The thickness of each part ensured that radiation entering the detector from any direction had to pass through more than $1.5 \mathrm{~cm}$ of lead. The width of the window was determined as $0.8 \mathrm{~cm}$ after several test measurements, based on the sensitivity of the measured profiles and the time required for measurements.

In each of monitoring places we made a borehole in the soil using a hand auger, into which we inserted a vinyl chloride pipe that measured $0.6-1.3 \mathrm{~m}$ in length, $85 \mathrm{~mm}$ internal diameter, and $89 \mathrm{~mm}$ external diameter. The scintillation probe with a lead collimator was suspended in the monitoring pipe using a rope to measure the gamma-ray intensity at each depth. We added a fin to the root of the collimator to prevent it from tilting in the pipe. 

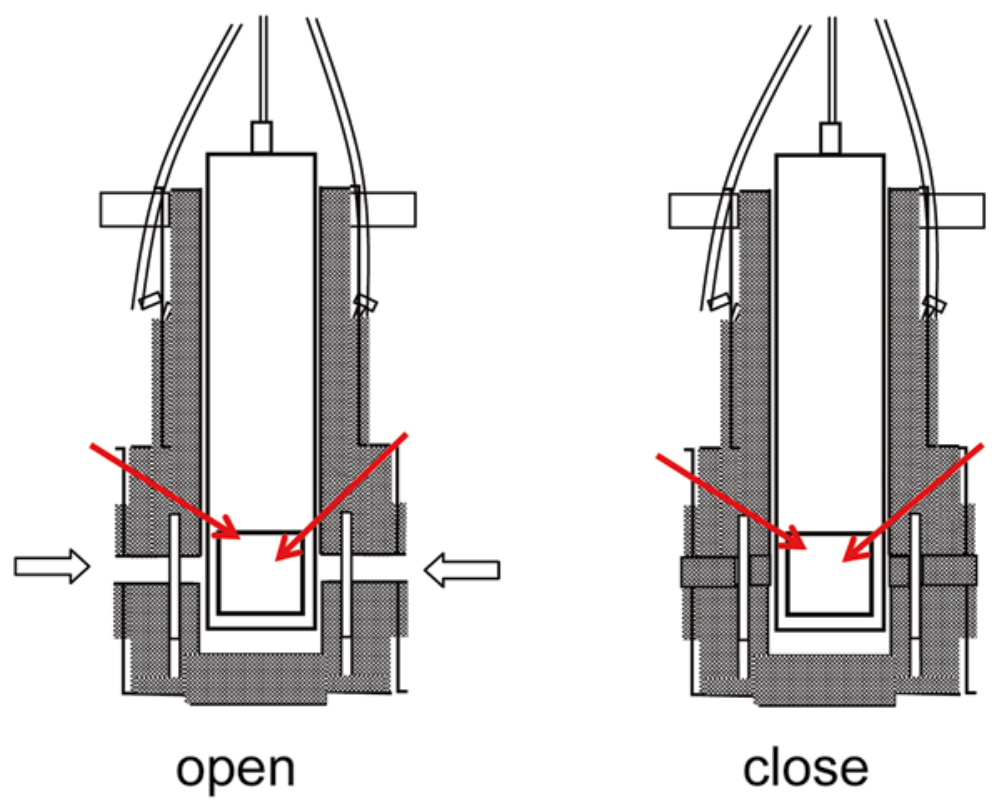

\section{Inflow from window = open - close}

Fig. 6.4 Method for correcting insufficient lead insulation of the collimator

\subsubsection{Method for Correcting Insufficient Collimator Lead Shielding}

The thickness of the lead shielding of the collimator was insufficient and the lead itself emitted some gamma rays. These noise, radiation leaks, and any other undesirable radiation had to be subtracted from the measured radiation intensity to determine the radiation that exclusively entered the slit window. In order to cancel the noises, we added a measurement in which the slit window was plugged with lead (Fig. 6.4). The correct value of the radiation intensity at each depth in the monitoring pipe was obtained by subtracting the value measured with the plugged window collimator at the same depth from the value measured with the open window collimator. Using this method, the corrected radiation distribution reflected the actual distribution of $\mathrm{Cs}$ concentrated at the soil surface more sharply, as shown in Fig. 6.5. The time required to measure the radiation intensity at each depth in the monitoring hole was $25-50 \mathrm{~s}$, depending on the amount of $\mathrm{Cs}$ present $\left(\mathrm{Bq} / \mathrm{m}^{2}\right)$ at each site. 
Fig. 6.5 Effects of correction for leakage through the lead insulation of the collimator. An example measured in Koriyama is shown

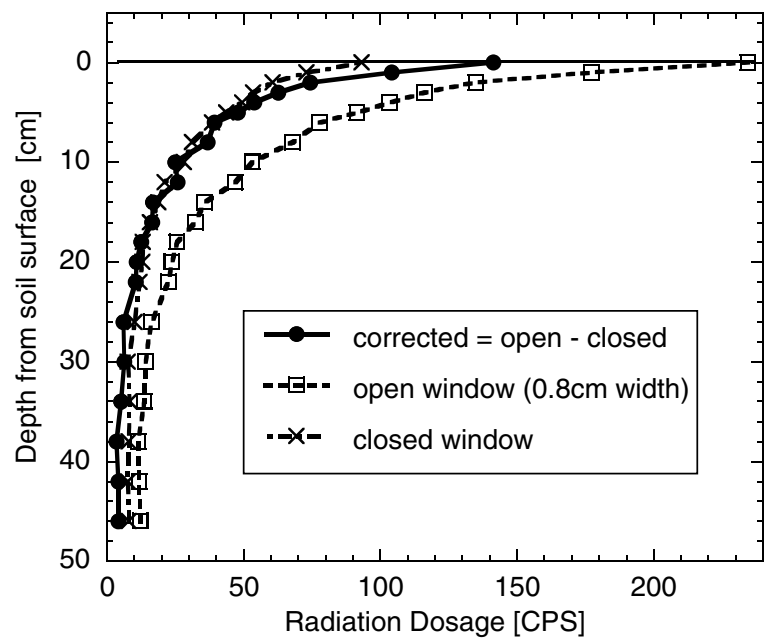

\subsubsection{Calculation of the Cs Migration Distance}

The average Cs migration distance was determined based on the center of the vertical radiation intensity (or concentration) profiles, which was calculated as follows:

$$
\langle x\rangle=\frac{\sum_{i} x_{i}\left(\mathrm{c}_{\mathrm{i}}-\mathrm{c}_{0}\right) \Delta x_{i}}{\sum_{i}\left(\mathrm{c}_{\mathrm{i}}-\mathrm{c}_{0}\right) \Delta x_{i}}
$$

where $\mathrm{c}_{\mathrm{i}}$ is the measured radioactive intensity (or Cs concentration) at depth of $x_{\mathrm{i}}$, and $\Delta x_{\mathrm{i}}$ is the interval of the measured depth, and $\mathrm{c}_{0}$ is the average radioactive intensity (or Cs concentration) in the deep soil layer where $c_{i}$ does not decrease with depth.

For the profile obtained by soil sampling where $\mathrm{c}_{\mathrm{i}}$ was the actual Cs concentration, the center of the profile $\langle x\rangle$ in Eq. (6.4) indicates the average Cs migration distance during the period after Cs fallout (late March 2011). For the profiles measured in situ in the monitoring holes, the average Cs migration distance between the two time points was determined by the difference in the centers of the two profiles.

\subsection{Results and Discussion}

Figure 6.6 shows a comparison of the vertical radiation profiles at two time points, which were measured in the monitoring boreholes at each location, and the radiocesium concentration profile at the first time point for the sampled soil in each hole (right-hand side). The soils in the locations were not disturbed after the Cs fallout. It was apparent that the vertical radiation profiles measured in situ in the monitoring 

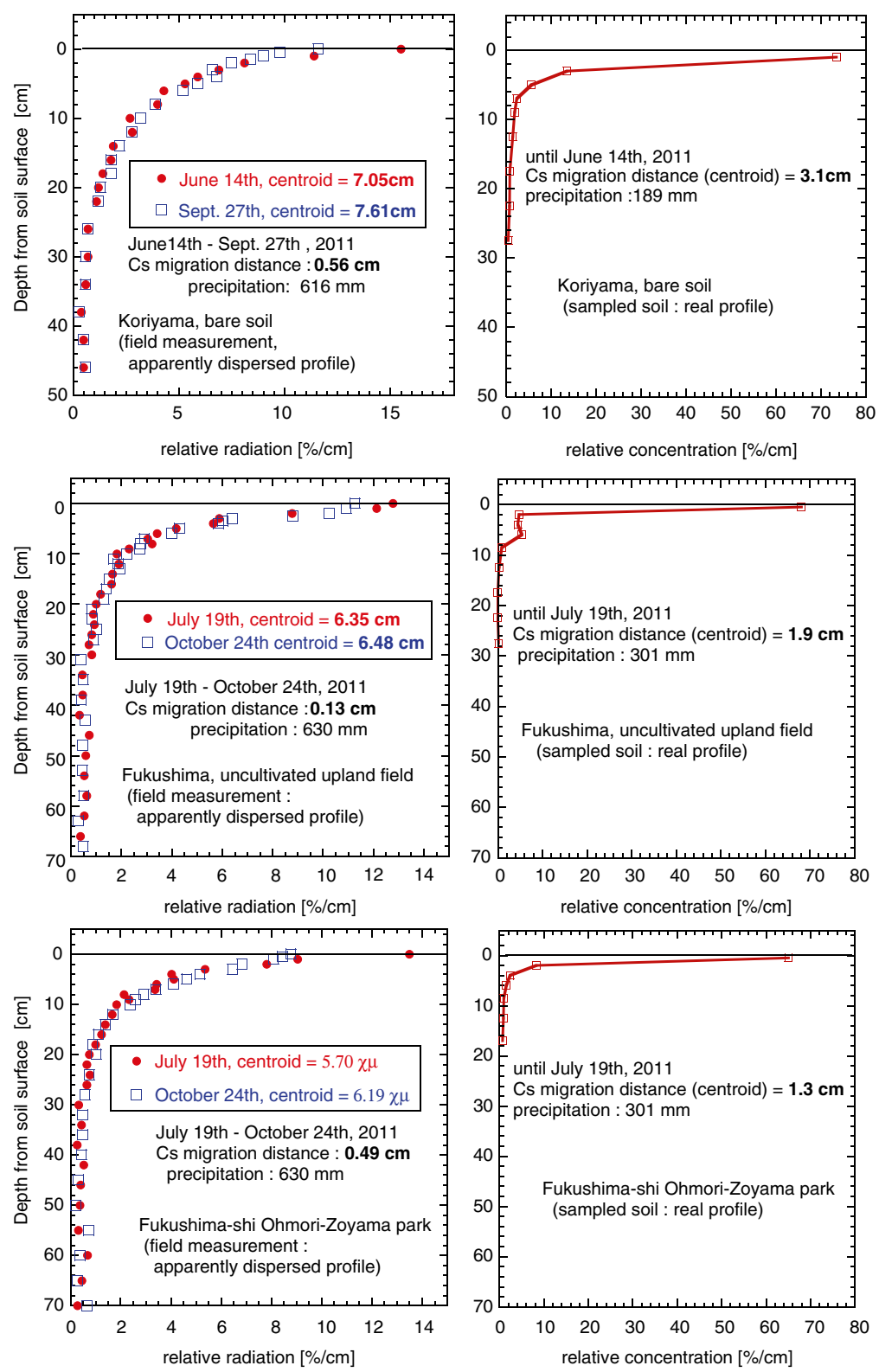

Fig. 6.6 Vertical radiation profiles at 2 time points measured in each monitoring borehole (left-hand side) and the radiocesium concentration profile at the 1st time point for the sampled soil from each hole (right-hand side). The soils were not disturbed in the locations after the radiocesium fallout. The depth of the centroid of each radiation/concentration profile is shown 

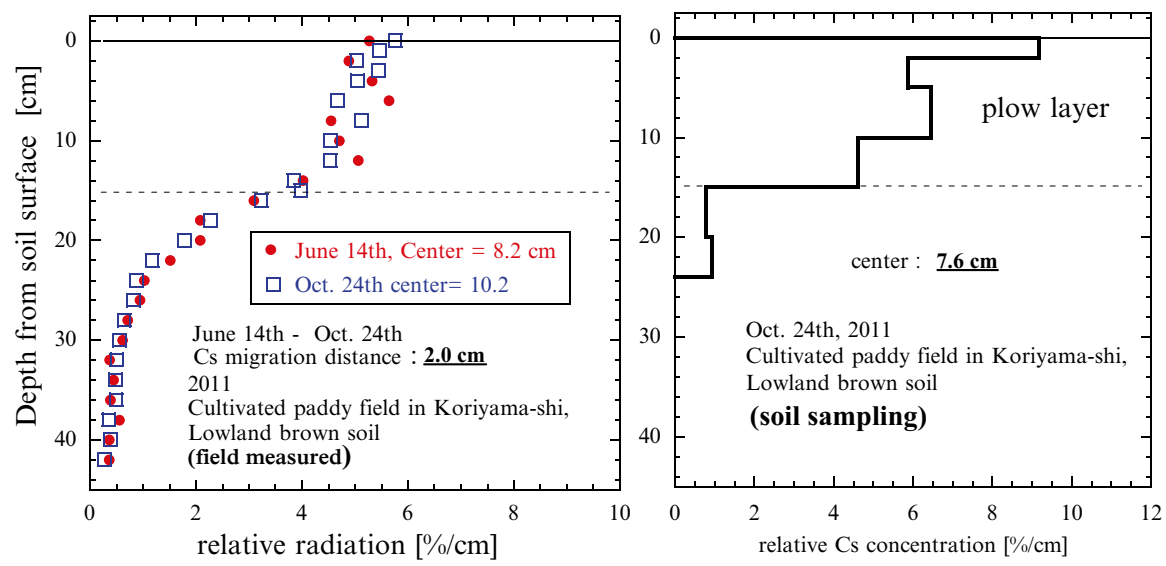

Fig. 6.7 Comparison of the vertical radiation profiles measured in the monitoring borehole (left-hand side) and the radiocesium concentration profile of the sampled soil (right-hand side) for a cultivated paddy field where a 0-15 cm layer was plowed and puddled with water in May 2011 after the radiocesium fallout

boreholes were highly dispersed and the location of the center was much deeper than the actual concentration profiles obtained from the sampled soil. This suggested that the radiation profiles measured in the monitoring holes did not accurately reflect the actual concentration profiles when the gamma-ray source was concentrated in a thin soil surface layer. There are two reasons for the measured radiation profiles to be dispersed. First, the slit window of the collimator was not sufficiently narrow compared with its depth to restrict radiation incoming from inclined direction other than horizontal direction. Second, the scintillation survey meter used in the study detected gamma rays scattered throughout the soil as well as those emerging directly from the radiation source $(\mathrm{Cs})$. Therefore, the in situ radiation profiles were more dispersed than the actual concentration profiles when the source was concentrated in a thin surface layer. Figure 6.7 shows the profiles for a cultivated paddy field where a $0-15 \mathrm{~cm}$ deep plowed layer was mixed and puddled before the monitoring hole was created. For such vertically distributed gamma-ray source, the radiation profile measured in the hole accurately reflected the gammaray source concentration profile.

Although radiation profile measured in the monitoring hole was considerably dispersed and did not reflect the actual radiocesium concentration distribution, the difference in the depth of the centers of the profiles at the two time points may accurately reflect the average migration distance of the radiocesium during this period.

The migration distances between the two time points detected by in situ radiation monitoring and the initial migration distances obtained from the first soil samples are summarized in Table 6.1, with the precipitation data during these periods. The initial migration distance for 2-3 months after the radiocesium fallout (late March 2011) until the first soil sampling was $13-22 \mathrm{~mm}$, which was approximately $1 / 10$ th- 
Table 6.1 Average distance of radiocesium migration in the soil based on the centroids of the radiation profiles measured in the monitoring boreholes

\begin{tabular}{|c|c|c|c|}
\hline & $\begin{array}{l}\text { Field containing } \\
\text { flowering trees } \\
\text { (Koriyama-shi) } \\
\text { Brown lowland soil } \\
620 \mathrm{kBq} / \mathrm{m}^{2} \\
\end{array}$ & $\begin{array}{l}\text { Uncultivated } \\
\text { upland field } \\
\text { (Fukushima-shi) } \\
\text { Brown lowland soil } \\
350 \mathrm{kBq} / \mathrm{m}^{2}\end{array}$ & $\begin{array}{l}\text { Ohmori-Zoyama } \\
\text { Park (Fukushima-shi) } \\
\text { Brown forest soil } \\
480 \mathrm{kBq} / \mathrm{m}^{2}\end{array}$ \\
\hline $\begin{array}{l}\text { Period } 1 \text { from March 11th, } \\
2011\end{array}$ & To June 14th, 2011 & To July 19th, 2011 & To July 19th, 2011 \\
\hline $\begin{array}{l}\text { Depth of the centroid (for } \\
\text { soil sampling) }\end{array}$ & $21.6 \mathrm{~mm}$ & $19 \mathrm{~mm}$ & $13 \mathrm{~mm}$ \\
\hline Precipitation $(\mathrm{R})$ & $189 \mathrm{~mm}$ & $301 \mathrm{~mm}$ & $301 \mathrm{~mm}$ \\
\hline Period 2 & $\begin{array}{l}\text { To September 29th, } \\
2011\end{array}$ & $\begin{array}{l}\text { To October 21th, } \\
2011\end{array}$ & $\begin{array}{l}\text { To October 21th, } \\
2011\end{array}$ \\
\hline $\begin{array}{l}\text { Distance between the } \\
\text { centroids of the two } \\
\text { profiles }\end{array}$ & $9.7 \mathrm{~mm}$ & $2.3 \mathrm{~mm}$ & $4.9 \mathrm{~mm}$ \\
\hline Precipitation (R) & $616 \mathrm{~mm}$ & $630 \mathrm{~mm}$ & $630 \mathrm{~mm}$ \\
\hline Period 3 & To March 28th, 2012 & To March 27th, 2012 & \\
\hline $\begin{array}{l}\text { Distance between the two } \\
\text { centroids }\end{array}$ & $5.4 \mathrm{~mm}$ & $2.0 \mathrm{~mm}$ & \\
\hline Precipitation $(\mathrm{R})$ & $340 \mathrm{~mm}$ & $315 \mathrm{~mm}$ & \\
\hline
\end{tabular}

The three locations were bare soil that received radiocesium fallout

$1 / 20$ th of the water molecule migration rate, given that the average migration distance of water molecules $(\mathrm{q} / \theta)$ was similar to or twice the depth of precipitation $(\mathrm{R})$ based on the Japanese meteorological conditions and the soil water content in the locations. However, after June 2011, the velocity decreased to 1/10th of that in the early period, i.e., to approximately $1 / 200$ th of water molecules.

In the 2-3 months after the radiocesium fallout in late March 2011, Cs was fairly mobile accompanied by the soil water movement; however, its mobility decreased remarkably after this period. Further evidence also suggested that Cs remained fairly mobile until May 2011, i.e., 2 months after the Cs fallout, because the soil samples from the cultivated paddy field shown in Fig. 6.7, which were taken from the subsoil below the plowed layer (below $15 \mathrm{~cm}$ ) in late May (before water filling), contained high levels of Cs (15-20\%). This suggested that Cs was moved from the plowed soil into the undisturbed sublayer by rainfall, after plowing in early May.

The results shown in Table 6.1 indicate that strong Cs fixation occurred over a course of few months. The Cs fallout accompanied weak rainfall during late March 2011, after the nuclear plant accident. It is considered that the form of Cs present in the fallout was mostly that of soluble ion and not the form attached to solid particles because a large amount of the Cs fallout was fixed to the smooth surfaces of trees and their leaves by Coulomb force. The fixed Cs on trees was not washed away by rainfall $(\geq 600 \mathrm{~mm})$, and half of the radiocesium fallout was still present on trees above the ground in the summer of 2011. When the radiocesium fallout came in contact with the soil surface, it was immediately fixed to the soil by Coulomb force 


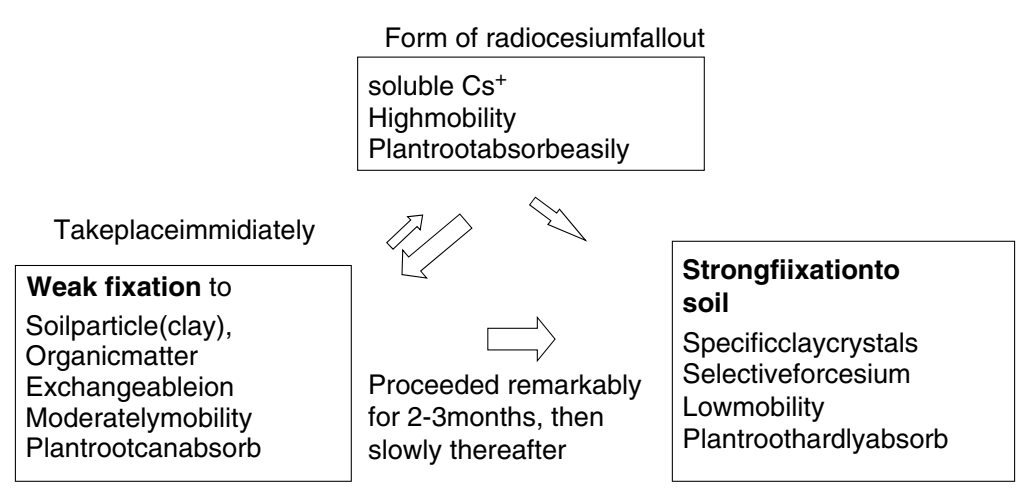

Fig. 6.8 Forms of radiocesium present in the soil and their dynamics

and to any organic material that covered the soil surface. This initial fixation to the soil or organic material was weak because of which the fixed Cs could be replaced by other cations in the soil water that were present as soluble ions and thus, they were relatively mobile in the water flow. Although weak fixation may occur immediately, Cs can also be gradually transferred into a state of strong fixation at specific sites on the inner surfaces of silicate crystal clay sheets (Fig. 6.8). The radiocesium migration analysis in the present study indicated that the transfer to strong fixation typically proceeded over a course of few months after the fallout, until June 2011 in the soils in Fukushima. The radiocesium concentrations in vegetable samples produced in Fukushima Prefecture dropped to almost "not detected" after July 2011; however, previously, some samples were detected (>10 Bq/kg) for which the radiocesium was considered to be transferred from the root. The transfer of radiocesium from weak fixation to strong fixation must have prevented the plant root uptake as well as the decreased rate of migration in the soil.

\subsection{Conclusion}

The velocity of the convective movements of radiocesium was $1 / 10$ th $-1 / 20$ th of that of water molecules in the soil during the first 3-4 months after the Cs fallout, from late March 2011 to June or July 2011, but it declined rapidly to 1/100th-1/200th of water molecules during the next 8-9 months (up to March 2012). This remarkable reduction in the Cs migration rate indicated a change in the Cs transfer from weak fixation to strong fixation to soil over a course of few months, which would also have been accompanied by a remarkable reduction in the Cs transfer from soil to plants through root uptake. Therefore, according to the long-term field investigations of Cs fallout after atmospheric nuclear weapon testing and the Chernobyl accident, the Cs mobility in soil will decrease slowly year after year. 
Open Access This article is distributed under the terms of the Creative Commons Attribution Noncommercial License which permits any noncommercial use, distribution, and reproduction in any medium, provided the original author(s) and source are credited.

\section{References}

Cremers A, Elsen A, Depreter P, Maes A (1988) Quantitative analysis of radiocesium retention in soils. Nature 335:247-249

IAEA (2010) Handbook of parameter values for the prediction of radionuclide transfer in terrestrial and freshwater environments. Tech Rep Ser 472:1-194

Kamei-Ishikawa N, Uchida S, Tagami K (2008) Distribution coefficient for Sr-85 and Cs-137 in Japanese agricultural soils and their correlations with soil properties. J Radioanal Nucl Chem 277:433-439

McBride MB (1994) Environmental chemistry of soils. Oxford University Press, New York, pp $1-416$

Rosen K, Oborn I, Lonsjo H (1999) Migration of radiocaesium in Sweden soil profiles after the Chernobyl accident. J Environ Radioact 46:45-66

Shiozawa S, Tanoi K, Nemoto K, Yoshida S, Nishida K, Hashimoto K, Nakanishi T, Nihei N, Ono Y (2011) Vertical concentration profiles of radioactive cesium and convective velocity in soil in a paddy field in Fukushima. Radioisotopes 60:323-328 (in Japanese) 